Portland State University

PDXScholar

\title{
To Love a Highly Sensitive Person: a Theoretical Study on Romantic Relationships and Sensitivity
}

\author{
Rose Sherman \\ Portland State University
}

Follow this and additional works at: https://pdxscholar.library.pdx.edu/honorstheses

\section{Let us know how access to this document benefits you.}

\section{Recommended Citation}

Sherman, Rose, "To Love a Highly Sensitive Person: a Theoretical Study on Romantic Relationships and Sensitivity" (2017). University Honors Theses. Paper 394.

https://doi.org/10.15760/honors.391

This Thesis is brought to you for free and open access. It has been accepted for inclusion in University Honors Theses by an authorized administrator of PDXScholar. Please contact us if we can make this document more accessible: pdxscholar@pdx.edu. 
To Love a Highly Sensitive Person: A Theoretical Study on

Romantic Relationships and Sensitivity

by

Rose Sherman

Portland State University

An undergraduate honors thesis submitted in partial fulfillment of the requirements for the degree of

Bachelor of Arts

in

University Honors

and

Social Science

Thesis Advisor

Dr. Karen Chenier

Portland State University 


\begin{abstract}
The Highly Sensitive Person was a term first established by Dr. Elaine Aron in the 1990’s that distinguished the experience of individuals with Sensory Processing Sensitivity, a neurological but neutral, psychological trait. The current population of Highly Sensitive People (HSP) makes up 15 to 20 percent of the population and interacts within 36 percent of romantic relationships. In this body of theoretical research, I outline the ways in which Highly Sensitive qualities affect committed, romantic, monogamous relationships by firstly determining the borders of what defines an HSP, then what makes a "successful" romantic relationship and the constraints of such a definition, and finally implementing the HSP qualities into these terms. I have found that "success" within a romantic relationship is supported by an emphasis on communication, healthy boundaries, a 5:1 ratio of positivity to negativity, and a rich and shared intimacy between partners. HSPs fare well within such relationships, as they are defined by their emotional awareness and depth, their empathy towards others and their partner, and their ability to communicate their needs. The "success" of a relationship involving an HSP is largely dependent on the ability of the HSP to recognize their own threshold for overarousal or overstimulation and to communicate these needs to their partner. The ultimate "success" of a romantic relationship comes from mutual understanding and compassion, the likes of which are supported by the inherent qualities of the Highly Sensitive Person.
\end{abstract}

Keywords: Highly Sensitive Person, HSP, sensitivity, trait, interpersonal relationships 
To Love a Highly Sensitive Person: A Theoretical Study on

Romantic Relationships and Sensitivity

"We cultivate love when we allow our most vulnerable and powerful selves to be deeply seen and known." - Brené Brown

Though one might reasonably assert that being in love is already a condition wrought with vulnerability, this experience is heightened when one or both partners are especially vulnerable themselves. If the term "vulnerable" is replaced with "sensitive", then it is worth investigating what one does when they are not only in a committed, romantic partnership, but also identify as a Highly Sensitive Person. The trait associated with being Highly Sensitive, coined by psychologist Dr. Elaine Aron in the mid-1990's, is also known as "Sensory Processing Sensitivity" (Aron, 2000, p. xiii). However, for the sake of consistency, I will refer in my writing to individuals on this particular spectrum of sensitivity as Highly Sensitive People (HSP). The trait, which has been described by Aron as distinctly neutral, unlike other conditions and disorders involving similar sensitivities (Aron, 2017), affects some 15 to 20 percent of the population (Aron, 1997, p. xiii). As a result of this significant of a percentage, the likelihood of interacting with an HSP is also quite high; Aron estimates that the chance of a relationship being affected by the trait is at least 36 percent (Aron, 2000, p. 3). Thus, approximately one in every three individuals will be in some form of a relationship with an HSP, if they do not identify as one themselves.

It is curious, then, that we do not hear about the HSP experience more often. This invisibility may be linked to cultural influences, which in many cases have little to no representation of what a Highly Sensitive individual might look like. For example, in Western culture, the association with identifying as "sensitive", and what's more, "Highly Sensitive", is 
seen as a negative characteristic, especially when it comes to romantic partnerships (Kapoor, 2015; Lally, 2015; Hill, M., 2017). “What is the ideal in our culture?” reiterates Aron in her 1997 book, The Highly Sensitive Person, "Movies, advertisements, the design of public spaces, all tell us we should be as tough as the Terminator, as stoic as Clint Eastwood, as outgoing as Goldie Hawn" (p. 15). Aron chooses these particular examples to exemplify certain culturally accepted personality characteristics: Terminator features an extremely masculine character, Clint Eastwood's characters show little to no emotion, and Goldie Hawn acts as a figurehead of extraversion. The HSP, in contrast, offers a very separate schema to work with, no better or worse than those listed above (Aron, 1997).

From research on romantic relationships, marriage, and partnerships, it can be asserted that there is no one type of "successful” love. In Dr. John Gottman's studies on happy marriages, for example, he often demonstrates that commitments can look vastly different and still operate with the same love and support as any another (Gottman, 1994, p. 32). In these terms, HSPs are certainly able to experience loving, "successful" romantic relationships. The real question posed is, instead, how the qualities of the HSP affect these committed bonds. Through first analyzing what defines the HSP experience, then understanding what constitutes a "successful" romantic relationship, I will utilize the literature to provide a framework with which to answer this question. Moreover, this analysis will allow for an understanding of where future research needs to be conducted on HSPs in romantic relationships. Though there are difficulties inherent in being in relationship with or as a Highly Sensitive Person, there are also many positive qualities such as emotional depth and self-awareness, high levels of awareness of one's partner, proficiency in communication, and a rich depth of intimacy that benefits any couple (Gottman, 1994; Aron, 1997). 


\section{The Highly Sensitive Person}

Dr. Elaine Aron defines the Highly Sensitive Person by way of an acronym called "DOES" (Aron, 2000, p. xv). A simple method of understanding what distinctly qualifies the HSP, each letter of "DOES" stands for a different element of the trait. Aron writes in her author's note from 2016 that " $\mathrm{D}$ is for depth of processing, [...] followed by easily overstimulated. If you process everything deeply and if there's too much to process, $\mathrm{O}$ is the result. $\mathrm{E}$ is for emotionally responsive and empathy, both of which the research is uncovering more and more. Finally, $\mathrm{S}$ is for sensitive to subtle stimuli” (p. xv).

Thus, by using "DOES", the groundwork is laid out to systematically understand the qualities of the HSP experience. These four letters and their corresponding sentiments organize something of a spectrum, as Aron explains in several of her books on the subject (Aron, 1997; Aron, 2000). To place oneself on this spectrum, Aron suggests the use of her self-assessment (Aron, 1997, p. xxi). The "HSP test" offers twenty-two statements to mark if true, including sentiments such as "Other peoples moods affect me", "I am bothered by intense stimuli, like loud noises or chaotic scenes" and "I am deeply moved by the arts or music" (Aron, 1997, p. xxi). If the participant marks twelve or more of these statements as true about themselves, they would qualify as Highly Sensitive. However, if somewhere between nine and eleven of the statements were marked by the participant, Aron still considers these individuals to be within this relative spectrum of sensitivity (Aron, 1997, p. xxii). These findings, then, may imply that sensitivity, despite certain cultural biases against it, is more common than is discussed (Kapoor, 2015; Lally, 2015; Hill, M., 2017). Regardless, it is worth understanding Aron's spectrum of sensitivity and, more specifically, the spectrum of the Highly Sensitive Person: the former end being at normal levels of sensitivity and the latter being at unusually high levels of sensitivity, approaching a 
realm of disorder (Aron, 2017). The specific use of a spectrum is also significant because it differs from the categorical approach that is often employed in diagnosing mental health, specifically in the Diagnostic and Statistical Manual of Mental Disorders (Akiskal \& Benazzi, 2006, Miller, 2014). A spectrum approach allows for an awareness of the nuances within a condition, as in the case of the Highly Sensitive Person (Aron, 1997; Akiskal \& Benazzi, 2006).

The self-assessment tool, then, allows for the individual to identify as existing somewhere on this spectrum. This allows for a clearer understanding of each letter within Aron's acronym, "DOES", an important supplement to the initial "HSP Test" (Aron, 1997). The "D" within "DOES", or Depth of processing, can be understood through the lens of Depth Psychology, as it relates to the individual's experience of cognitive introspection. Depth Psychology refers to "approaches to therapy that are open to the exploration of the subtle, unconscious, and transpersonal aspects of human experience” (C.G. Jung Center). One statement within Aron's self-assessment reads: "I have a rich, complex inner life" (Aron, 1997, xxi), which directly relates to the concepts addressed in Jung's and others work on Depth Psychology: ideas of inner awareness and eventual transformation (C.G. Jung Center). The HSP, as also supported by Jung's research on innate sensitivity, experiences this "complexity" by being more adept at delving within themselves to thereby process what occurs outside of themselves (Aron, 1997; Aron, 2004, p. 337).

Overstimulation, the "O" within "DOES", is a crucial element to the physiological diagnosis of the HSP. Statements like "I am easily overwhelmed by things like bright lights, strong smells, coarse fabrics, or sirens close by" and "I become unpleasantly aroused when a lot is going on around me" refer back to a concept Aron describes as "overarousability" (Aron, 1997, p. xxi; Aron, 1997, p. 6-8). This status of physical, non-sexual arousal is a concept Aron 
emphasizes due to its core role in the "sensory processing sensitivity", central to the experience of the HSP (Aron, 2017). As illustrated by the self-assessment statements, the HSP is " [ ...] a person who is more aware of everything going on outside and inside, plus is processing it more thoroughly", and therefore "will most likely wear out mentally and physically sooner than others and therefore become stressed." (Aron, 1997, p. xvii). Though all individuals, Highly Sensitive or otherwise, have to find the balance between overstimulation and understimulation or boredom, the HSP has a lower threshold for such states, particularly that of the former (Aron, 1997, p. 8, Miller \& Schaff, 2008).

The "E" in "DOES" stands for emotional sensitivity and empathy, or the ability to feel and understand others (Aron, 1997). These qualities are what most would commonly associate with the trait of sensitivity, in large part because high levels of empathy and emotion align with the culturally agreed upon definition of being "sensitive" (Aron, 1997; Aron, 2004; Hill, 2017). The dictionary defines "sensitive" as "easily hurt emotionally" and "delicately aware of the attitudes and feelings of others" (Merriam-Webster, 2017). HSPs are certainly more susceptible to emotional qualms, and their awareness of others is exactly what Aron's "E" entails (Aron, 1997). Additionally, just as they are aware of others' emotions, HSPs have been found to experience their own emotions with more intensity than those without the trait (Aron, 1997). While being emotionally sensitive does not necessarily mean being an emotional empath, a psychological term referring to being very empathetic (Smith, 2014; Orloff, 2017), the HSP's high levels of awareness similarly include awareness of the individuals around them. Dr. Orloff, a psychologist and author of the book The Empath's Survival Guide, writes that though “empaths share some or all of the traits of [...] HSPs", they "take the experience of the Highly Sensitive Person further. We can sense subtle energy, which is called shakti or prana in Eastern healing 
traditions, and we absorb this energy into our own bodies. Highly Sensitive People don't typically do that" (2017, p. 5). It is interesting, then, that the empath may even be more sensitive than the HSP, experiencing energy as well as emotion. To clarify the two traits and thusly implement something of a differential diagnosis, the HSP seemingly has less of a somatic experience than that of the empath (Orloff, 2017). Rather than "absorbing energy" or emoting on a bodily level, the HSP has higher functionality in their ability to emote more specifically on a mental or psychological level (Aron, 1997; Orloff, 2017).

Aron's self-assessment includes statements such as, "Other people's moods affect me" and "when people are uncomfortable in a physical environment I tend to know what needs to be done to make it more comfortable (like changing the lighting or the seating)" (Aron, 1997, p. xxi). The Highly Sensitive Person is just that: Highly Sensitive, both in responding to their environments, their own inner processing, and the people with which they surround themselves even if this may exclude those people's "shakti" (Orloff, 2017, p. 5).

Finally, the " $S$ " in DOES relates back to overarousability: the sensitivity to stimuli. This is similar to the "O" of overstimulation in Aron's "DOES", though the " $\mathrm{S}$ " is closer to Aron's definition of the HSP having a "sensitive nervous system" (Aron, 1997, p. xiii). Not only are HSPs psychologically prone to overarousal due to cognitive processing, but physiologically as well (Aron, 1997). In Aron's further research on the subject of "sensitivity to stimuli", she found significance in "differential susceptibility" (Aron, 1997, p. xvi). This finding directly relates to the susceptibility an HSP might have to their environment, particularly in understanding their vulnerability to depression and anxiety (Aron, 1997, p. xvi).

The acronym "DOES" is a helpful tool in understanding what being Highly Sensitive might mean, though it is also important to keep in mind the spectrum on which sensitivity exists, 
and thusly the vast range of experiences a Highly Sensitive individual may have. Many articles published in pop-psychology resources and magazines following the introduction of the term by Aron in some ways broadened the audience and in other ways misconstrued or underrepresented the complexities of the concept (Biali, 2011; Smith, 2014; Kaufman, 2015; Ganahl, 2015). However, this information was an excellent means of outreach in a culture otherwise devoid of any understanding of sensitivity, and in many cases, biased against it (Kapoor, 2015).

One particular challenge in defining the qualities of the HSP is distinguishing a difference from mental disorders. In understanding the Highly Sensitive Person, it is also important to understand what it is not: thus, returning to the concept of establishing a differential diagnosis. For example, the sensitivity to stimuli aspect of the HSP, the "S" in "DOES", is parallel to that of individuals with Sensory Processing Disorder (SPD). SPD, as opposed to Sensory Processing Sensitivity, is the more extreme state of difficulty with overstimulation (Aron, 1997; Miller, 2014). Though Aron describes HSPs as having sensitivities on a neurological level (1997), SPD is a "complex neurological disorder" (Miller, 2014). In one article on children with SPD, the author writes that the "Diagnostic and Statistical Manual of Mental Disorders (DSM-5) [...] now includes hypersensitivity and hyposensitivity under the category autism spectrum disorder" (Miller, 2014). It is worth mentioning that Highly Sensitive People and Sensory Processing Sensitivity do not exist on the autism spectrum, nor do either have a presence in the DSM. This difference is significant because it draws a line between the two conditions; whereas SPD involves an individual suffering from a neurological disorder, an individual who is an HSP instead experiences the effects of what is closer in relation to a temperamental or personality trait (Aron, 1997; Miller, 2014; Liss et al., 2008). 
A mental disorder, in contrast from such a neutral trait, is an element that causes marked distress. Mental illness is broadly characterized as an individual experiencing "disorganization of personality, mind, or emotions" that, in turn, causes an inability to function: a "disruption in normal thinking, feeling, mood, behavior, interpersonal interactions" (Merriam-Webster, 2017). A differential diagnosis of the Highly Sensitive Person establishes, then, that the trait seemingly does not impair their functioning. In contrast, individuals who are diagnosed with mental illness suffer from their condition. Though it would be incorrect to suggest that Highly Sensitive People do not experience difficulties from their psychological differences, any amount of suffering is typically in conjunction with other conditions (Aron, 1997). For example, there have been several studies attempting to understand how the HSP may be more susceptible to mood or anxiety disorders. One particular study examined the relationship individuals who identify as HSP have to stress levels and symptoms of illness (Benham, 2006, p. 1439). The research found that they were "more likely to experience symptoms of ill health", and that the trait of heightened sensitivity tended to increase overall physical arousal, which was correlated with chronic or serious health consequences (Benham, 2006). The research went on to note, however, that HSPs may also be more susceptible to health risks as they are more aware of somatic symptoms; whereas other non-sensitive individuals may not have noticed certain minor physiological sensations or ailments, the HSP might be quicker to take note (Benham, 2006). Thus the HSP's self-awareness adds an additional level to their relationship with both their mental and physical health. This heightened awareness of such conditions relates to their state of mental well-being and, in turn, causes more stress alongside their illness (Aron, 1997; Benham, 2006). 
Based on Dr. Elaine Aron's research, the HSP experiences “differential susceptibility", illustrated by the heightened likelihood for depression or other related mental health concerns triggered by troublesome childhood experiences or trauma throughout formative years (Aron, 1997). Though Aron argues extensively on how being Highly Sensitive does not cause mood disorders, there are certainly elements of being Highly Sensitive that demonstrate correlations with depression, particularly if an HSP has experienced trauma (Aron, 1997; Aron, 2000). The HSP feels the aftermath of such negative and formative experiences at a higher level of intensity than a non-HSP might (Aron, 1997).

There are several similar disorders that involve negative formative childhood experiences and intersect with Highly Sensitive characteristics. For example, a study on individuals with Borderline Personality Disorder (BPD) notes that individuals who suffer from the disorder have a lower threshold for emotional stimuli, greater emotional reactivity, lower ability of emotional regulation, and longer duration of response to emotional stimuli (Jovev et al, 2011). The research also found that there are connections between the emergence of BPD and biological factors or environmental influences, including the environment an individual experienced in childhood (Jovev et al, 2011). Arguably, a majority of the listed qualifications link and show similarities to Highly Sensitive People. The most salient intersection is that individuals with BPD have a lowered threshold for emotional regulation. Both Highly Sensitive individuals and those with BPD experience a difficulty returning to baseline arousal. Additionally, both conditions involve a susceptibility to the influences of their environment (Aron, 1997; Jovev et al, 2011). However, this is where the overlap in their symptoms ends. Individuals with Borderline are often in great 
distress as a result of their disorder. While their BPD does make their emotional arousability threshold lowered like that of an HSP, they are less aware of their emotional processing and at times are distinctly unaware of the ways that their emotions affect the people around them (Jovev et al, 2011). If only the HSP could be so lucky, their sensitivity often making them painfully aware of the opinions of others (Aron, 1997; Aron, 2000). In related findings, there is some intersection between individuals who are Highly Sensitive and individuals who have Narcissistic Personality Disorder: both can develop dependency on the people around them for security and sense of self (Ronningstam, 2010). However, HSPs differ in their empathetic nature; narcissists are defined by their inability to remove themselves from their own self-orientation and tend to lack empathy altogether (Aron, 2004; Ronningstam, 2010; Orloff, 2017).

The condition of the HSP, then, is distinct. Though it does involve sensitivity to sensory input, it is not a disorder in the vein of Sensory Processing Disorder; nor does it connect to the experience of the autism spectrum. Though the HSP experiences extremely strong emotions that may, in certain cases, be deeply affected by childhood trauma, the HSP does not manifest emotions or behavior in the same way that an individual with Borderline Personality Disorder might. Other related conditions may be alexithymia, the inability to describe the emotions one is feeling, such as when an HSP feels indescribably overaroused; and hypersensitivity, which has been described as a coping method rather than the biologically rooted Sensory Processing Sensitivity (Schwartz, 2012; Aron, 2017). Finally, though the HSP may experience depression and anxiety, these are more often linked to previous trauma and the inherent susceptibility to such environmental causes, rather than any predetermined likelihood to suffer from such conditions (Aron, 1997). 
Therefore, with the understanding that the Highly Sensitive Person exists as a neutral trait rather than a disorder, it is also important to place some of the HSP traits on a relative personality scale. In the "Highly Sensitive Person Scale", separate from the "HSP Test", Aron formulated several measures by which to place an individual on the spectrum of sensitivity (Aron, 1997, p. xxii). In one particular psychometric evaluation of this scale, Smolewska et al found that Aron's structure involved,

Aesthetic Sensitivity (AES), Low Sensory Threshold (LST), and Ease of Excitation (EOE). [...] In addition, the components had different patterns of association with the '‘Big Five'. More specifically, AES showed the strongest relation with Openness to Experience, while LST and EOE were found to be most closely associated with Neuroticism. (2006, p. 1269) The "Big Five" mentioned by this particular study refers to a personality test created by psychologists Paul Costa and Robert McCrae in the 1970's (Psychometric Success, 2017). As the test was being developed, an emphasis was placed on finding the five major personality traits that all human beings exist on some spectrum of, regardless of culture or language. These traits include, as related to Highly Sensitive People, "Neuroticism", "Openness to Experience", "Conscientiousness", and beyond that, "Extraversion" and "Agreeableness" (Psychometric Success, 2017). Though the experience of any person, HSP or otherwise, may not be reduced to five characteristics, it is interesting to find the intersections by which HSPs find themselves on such scales. For example, if an HSP tends to score high on neuroticism and low on extraversion, it does not mean that all HSPs are neurotic and introverted. In fact, Aron takes careful note of the 30 percent of HSPs that are extroverts (Aron, 1997, p. 98). It would seem an obvious correlation to place sensitive individuals who need time to retract from sensory stimulus as introverted, and 
what's more, shy. However, Aron argued against this, taking careful note of the individuality of the HSP. She suggested renaming an HSP's "shyness" as "social discomfort", typically resulting from overarousal, which may make one display the negative characteristics associated with a lack of social skills (Aron, 1997, p. 17). The HSP may feel a desire to withdraw socially as a means of avoiding this state of overarousal, employing coping mechanisms before the discomfort even exists (Aron, 1997, p. 94).

Historically, without the terminology of Sensory Processing Sensitivity or the popularization of the Highly Sensitive Person, there has always been information on sensitive or introspective individuals. Though these traits were often documented under the guise of introversion or shyness, there was certainly mention of sensitivity as well (Aron, 1997; Aron, 2004). As was mentioned earlier in referencing depth psychologist Carl Jung, he wrote extensively on the subject of "sensitiveness" and its innate qualities (Aron, 2004).

To reestablish a definition of these qualities, both of sensitivity and more specifically the Highly Sensitive Person, it would be best to return back to Aron's initial acronym, "DOES" (Aron, 1997). Being Highly Sensitive involves Depth of processing, Overarousability, Emotional sensitivity and high Empathetic tendencies, as well as Sensitivity to sensory stimuli (Aron, 1997, p. Xv).

All of these qualities make for an individual whose experiences exist through a sensitive lens: however, such individuals do not do so in a void, separate from other non-sensitive peers. Considering that HSPs make up 15 to 20 percent of the population, what happens when they interact with the remainder? Even more importantly, what happens when they fall in love? Before analyzing how these traits come into play within a romantic relationship, I will first 
determine how one might define a "romantic relationship", as well as how one might define a "successful" one.

\section{"Success" in Romantic Relationships}

To begin, it is important to clarify several features within this section due to the limitations of this thesis. There is a vast range of definitions when it comes to relationships, whether this means the actual nature of the relationship (monogamous vs. polyamorous), the sociological context of the relationship (race, sexual orientation, socioeconomic status, gender expression, etc), or the legal implications of the relationship (married, cohabitating, long-term, short-term) (McCandless \& Sullivan, 2016). It would be difficult, then, to have one clear definition of a relationship, much less a "successful" one. However, for the purposes of continuing on with this particular analysis of research, the "relationships" described will be largely those that are monogamous, for the most part hetero-normative or heterosexual in nature, and committed - whether in cohabitation or in marriage. There is a distinct need for further research on the many other forms of relationships that exist, and though they may not be covered in this particular body of work, there is no current research proving that any deviations from the "normative" relationships described lead to a less "successful" relationship.

Also, it is relevant to this particular question of "success" to mention that marriage by no means is the end goal of a relationship; as a disclaimer, many relationships do not result in marriage or cohabitation. Therefore, despite the use and mention of data and information from researchers and psychologists who focus on happy marriages, a happy relationship may be, at times, even more "successful” without this legal element (Gottman, 1994).

In continuing, I will be defining a "relationship" as a romantic, committed, monogamous bond between two individuals. Furthermore, the "success" of this relationship is dependent on 
some level of contentment between both partners. To operationalize "contentment", I will employ verbal statements utilizing synonyms: a relationship where both parties feel contentment implies that they are to some degree "happy", "satisfied" with the outcome and trajectory of their relationship, as well as feel "fulfilled" by the bond they share with one another (Thesaurus, 2017).

It would be easy in Western society to assume that this level of contentment within one's relationship means following the path of marriage (Coontz, 2005). However, historically, marriages do not actually reflect many of these qualities (Westermarck, 1926). In fact, it wasn't until relatively recently that marriages were bonds of love, and even more recently still that there were options for what defined a relationship outside of a marriage. In his book on the subject, Shumway describes a brief history:

Since marriage was increasingly seen as a private matter, it could no longer be justified as the exclusive legitimate context for sexual relations. People began experimenting more openly and in larger numbers with various alternatives to marriage, including heterosexual and homosexual practices. From the late nineteenth century through the mid-twentieth centuries, courtship and marriage continued to be the very powerful norm, but by the 1960 s, a new term, relationship, has emerged to cover the new variety of commonly practiced erotically invested bonds between individuals. Marriage was now only one alternative, albeit still the dominant one, in which intimacy might occur. (2003) This research sheds some light on the modern understanding of intimacy as a multi-faceted element of relationships, not limited to marriage and not emphasized within marriage before a certain point in the nineteenth century (Shumway, 2003). Intimacy is a crucial element of a "successful" relationship: intimacy promotes connection between partners and forges a bond, one 
not inherently sexual but emotional as well (Gottman, 1994; Aron, 1997; Shumway, 2003; Schnarch, 2009).

In many ways, intimacy is the progression of romance (Schnarch, 2009); to be intimate with one's partner means feeling emotionally safe, and experiencing what is exemplified as love or being "in love". It is possible to have emotional intimacy with friendships and other close interpersonal relationships; the romantic aspect to being in a relationship, however, creates the feeling of love that so many seek in finding mutual contentment (Gottman, 1994; Schnarch, 2009).

There are many ways that a relationship can lose such contentment, however. Challenges are natural and arise in relationships and marriages relatively often; it is a sign of marital health, so long as the couples can handle it well (Gottman, 1994). "If there is one lesson I have learned from my years of research it is that a lasting marriage results from a couple's ability to resolve the conflicts that are inevitable in any relationship" (Gottman, 1994, p. 28). Of the complications that can affect romantic relationships, anxiety and the role of attachment can play a major role in the ways that a couple interacts (Gottman, 1994; Aron, 2000). Personality has been found to affect the quality of a relationship, whether this means having personality characteristics that support the bond or traits that inadvertently sabotage the happiness of it (Demir, 2008). In one particular study on relationship satisfaction, Demi et al. found that in referring back to the Big 5 Personality Scale, Extraversion and Neuroticism had the highest correlation, positively and negatively, respectively. "[These traits] were related to happiness in the expected directions. Additionally, agreeableness and conscientiousness were found to be significant (positive) correlates of happiness. Finally, the relationship between personality and relationship quality were mostly in line with the hypothesis [...], with the exception of openness to experience not 
showing any relationship with romantic relationship quality" (2008). In understanding how the study found that personality and the individual personalities of each partner affect a happy relationship, it is worth noting that the more extraverted, agreeable, and conscientious a person was and the less neurotic they were, the better the quality of the bond. Later, this will play into the dynamics associated with the Highly Sensitive Person. There are many ways that the traits involved in the HSP experience cross over with those of other personality traits and conditions, including one's attachment style and social anxiety.

In an article written on adult attachment and the ways it may play a role in romantic relationships (Shaver \& Brennan, 1995), the authors wrote “[...] in 1987, Hazan and Shaver proposed that romantic love is an attachment process - a process of becoming emotionally attached to an adult romantic partner" (p. 267). Brennan et al go on to describe that "[...] these same three attachment types - secure, avoidant, and anxious-ambivalent - exist in adulthood and color the ways in which adults experience romantic love and behave in romantic relationships" (p. 267). Attachment style as an element of personality involves how a person feels about the security of the relationships they have with others (Shaver \& Brennan, 1995; Aron, 2000) and therefore would understandably affect their "success". For example, an individual with an insecure attachment style may experience the effect of such insecurities through the means of anxiety. General anxiety, and more specifically Social Anxiety Disorder, has been known to affect romantic relationships (Shaver \& Brennan, 1995; Porter \& Chambless, 2016; Porter et al., 2016). In several studies, it is interesting to find that female partners with this anxiety are more likely to be especially susceptible to partner criticism (Porter et al, 2016, p. 13) while male partners with the same affliction are a greater predictor for the couple breaking up (Porter \& Chambless, 2016). Therefore, these individual qualities 
may affect the level of contentment within a relationship, and in some cases, cause it to end entirely.

Dr. John Gottman has written many accounts on marriages and their according "success" (Gottman, 1994). Within his research, Gottman has found elements that lead to both the dissatisfaction and dissolving of a relationship as well as elements that lead to happiness and mutual understanding. In his research on the negatives that can poison a relationship, Gottman has outlined what he calls the Four Horsemen of the Apocalypse (Gottman, 1994). These include, in order, "criticism", "contempt", "defensiveness", and "stonewalling" (Gottman, 1994). Though these four elements exist as separate causes for conflict within the relationship, Gottman treats them as though they are steps leading to the path of divorce. When non-directed complaints become criticism, followed by contempt, there is deep dissatisfaction and lack of communication between the partners. This discontent and feeling of being attacked can lead both partners to feel defensive, and then to shut off entirely (Gottman, 1994). To offset this downward spiral, however, Gottman developed seven research-based principles for making relationships "harmonious" (Gottman, 1999). These principles include, "enhancing love maps", "nurturing fondness and admiration", "turning towards each other", "accepting influence", "solving solvable problems", "overcoming gridlock" and "creating shared meaning" (Gottman, 1999). The "love maps" that Gottman describes are a means to greater understanding of each partner's life through "mapping" the details: who they interact with and what they do in their own individual, day-to-day existence (1999). Gottman suggests increasing this understanding of one another, so as to best respect each other's individuality and experience. In the principle of "overcoming gridlock”, Gottman describes the discomfort of having opposing views and reaching a standstill. "The goal in ending gridlock is not to solve 
the problem, but rather to move from gridlock to dialogue", writes Gottman (1999, p. 217). Yet again, the emphasis is on respecting ones partner and allowing for processing to be a conversation. In his expanse of research, Gottman emphasizes the balance in relationships between positivity and negativity. Though the most important elements of a relationship should be "love and respect", he writes that the "[...] magic ratio [of positive and negative feelings] is 5 to 1 . In other words, as long as there is five times as much positive feeling and interaction between husband and wife as there is negative, we found the marriage was likely to be stable" (Gottman, 1994, p. 57). From this, it may be posited that happiness within a relationship comes from a balance: contentment and "success" is measured less in unanimity and a lack of conflict, but rather through harmony and mutual understanding, an emphasis on communication, and a shared sense of love, admiration, and respect (Gottman, 1994; Gottman, 1999).

Some relationships require more balance than others, however, particularly when there are distinct differences between the partners. There are many facets that go into an individual person's experience of contentment, and much more in the context of a romantic relationship. For example, if there are differences in personality types, it is perhaps even more complex than if both partners are extroverted than if one is and the other is distinctly not (Demir, 2008). In the case of a partnership involving an extrovert and an introvert, it is a question of thresholds: an extroverted individual may have a higher threshold for external stimulus and constancy of human interaction and a lower threshold for independence and time alone, and vice versa in the case of introversion (Aron, 2000; Cain, 2012). It may be especially difficult to see eye to eye in these relationships, though these are challenges that can be worked through. In Susan Cain's Quiet, a book on navigating life as an introvert, she writes on the dynamics between introverts 
and extroverts. "Introverts and extroverts sometimes feel mutually put off, but [...] research suggests how much each has to offer the other. Extroverts need to know that introverts - who often seem to disdain the superficial - may be only too happy to be tugged along to a more lighthearted place; and introverts, who sometimes feel as if their propensity for problem talk makes them a drag, should know that they make it safe for others to get serious" $(2012, \mathrm{p}$. 239). In suggesting that the differences between these characteristics may actually make communication stronger, Cain emphasizes that having partners with contrast may actually be a strength rather than a conflict.

Though Highly Sensitive People are not inherently introverted, introverts do make up some 70 percent of the Highly Sensitive population (Aron, 1997, p. 98). Thus, there may be similarities in the conflicts that arise from a difference in these levels of introversion, and similarities in the ways that these conflicts may be healed (Cain, 2012). There are also challenges that may come up from partnerships that involve one HSP and one non-HSP, rather than two. Interestingly enough, Dr. Aron finds that " $[\ldots]$ according to my data, about half of all HSPs have partners who are not HSPs" (Aron, 2000, p. 126). This supports the reality that nearly 50 percent of all HSP partnerships involve some sense of temperamental contrast between the two partners. Differences do not break relationships, however, they merely call for further employment of the tools that may offer some "success".

Relationships are affected by personality traits, attachment styles, negativity, and conflict; their success relies on awareness of these factors and an emphasis on communication (Gottman, 1994; Aron, 1997; Gottman, 1999; Aron, 2000). Contentment is born from the right balance: feelings of love, respect and admiration even in the face of difficulties. Though relationships differ across the board, these elements hold true throughout all reported successful 
marriages and partnerships (Gottman, 1994). So how does high sensitivity factor in? The Highly Sensitive Person brings many unique traits to their romantic relationships, and there are certainly many challenges that arise (Aron, 2000). That said, there are many positive elements that an HSP brings to the table. Thusly, I will next focus on how the Highly Sensitive Person may increase the likelihood of "success" as it has been so determined.

\section{Positive Characteristics of an HSP Partner}

Of the many stipulations involved in a "successful" relationship, many if not all of the most important focal points are centered on communication (Gottman, 1999). To reiterate both the positive and negative factors stated, the largest challenges and conflicts came from not being able to see eye-to-eye or being unable to communicate differences (Gottman, 1994) and the greatest joys came from communicating effectively and expressing feelings of genuine love and admiration for one another (Gottman, 1994). This is where the Highly Sensitive Person thrives. Dr. Elaine Aron offers the following sentiments in writing directly to HSPs, [...] Overall, sensitivity can greatly enhance intimate communication. You pick up on so much more of the subtle cues, the nuances, the paradoxes and ambivalences, the unconscious processes. You understand that this sort of communication requires patience. You are loyal, conscientious, and appreciative enough of the value of the relationship to be willing to give it the time. The main problem is, as always, overarousal. (p. 156) Here lies the outline for the positive elements of being in relationship with an HSP, or being an HSP in a romantic relationship. The Highly Sensitive Person is simply more aware of themselves, their inner processing, and their partner (Aron, 1997; Aron, 2000). This awareness, introspection, and ability to pick up on subtle cues are all exactly what a "successful" relationship asks of an attentive partner (Gottman, 1999). In being able to note what is going on 
both within the relationship and within their own experience, the HSP is a partner who is able to understand the nuances of what a non-HSP may overlook.

Alongside this awareness comes the ability to communicate it (Aron, 2000). Whereas a non-HSP may be unable to pick up certain subtleties in their partner, such as body language - a huge indicator of inner emotion, as described by Dr. John Gottman in his research (Gottman, 1994) - an HSP may not only note a shift in their partner's demeanor but also be able to convey this discomfort. To reinstate Gottman's Seven Principles: “enhancing love maps”, “nurturing fondness and admiration", "turning towards each other", “accepting influence", "solving solvable problems", "overcoming gridlock" and "creating shared meaning", many if not all of these sentiments involve being able to communicate efficiently and with compassion (Gottman, 1999). Compassion, love, and admiration are all within the HSP's arena: emotion. In feeling not only deep empathy but also experiencing an immense depth of emotion (Aron, 1997; Aron, 2000), HSPs have the benefit of not only being able to have these intense feelings but express them as well.

Being deeply in love, however, is not the only area of depth that the HSP is capable of. The Highly Sensitive Person thinks more deeply about their own thought processes, as well as about the world around them (Aron, 1997; Aron, 2000; Aron, 2004). This makes for an engaging partner in many ways: the HSP focuses on their own experiences, the meaning of their interactions with others, what others may be feeling, and on a larger scale, what meaning may lie in the greater world - one example being art, or social conscientiousness (Aron, 1997). "The reasons HSPs are valuable in relationships are fairly obvious - for example, we are conscientious, intuitive, aware of others moods, and eager to think deeply about what is going on," writes Aron (2000, p. 30). 
In "successful" relationships, there is the intimacy created by love, a feeling felt deeply by the HSP, and the trust that comes from communication, an area that the HSP is well versed in (Aron, 1997; Aron, 2000). But what happens when challenges arise from differences between an HSP and a non-HSP partner? Similar to the conflict discussed in the prior section, which defined relationships and "success", in its points on making amends between partners with different experiences (attachment style, temperament, social proclivities, etc), the HSP must often navigate the interplay and dynamics of other people and those that are different from them.

Apart from the HSP's ability to communicate well through their awareness, an essential and necessary part of navigating differences within relationships, there are many ways that the non-HSP partner would benefit from this bond. In a section specifically based on this type of arrangement, Aron writes that the non-HSP partner benefits by the ways that HSPs "notice subtleties, enjoying the good ones and changing the bothersome ones", "take their partners on HSP-type adventures", "prevent trouble, giving warning before the non-HSP would ever notice", and "create a healthier lifestyle for their non-HSP partners" (Aron, 2000, p. 130-131). In reference to a study on the ways that the Highly Sensitive trait may have evolved (Aron, Aron, \& Jagiellowics, 2012) it was generally determined that it was beneficial for some portion of the population to be extra-aware of their surroundings; "when a minority of individuals are responsive, they gain advantages that are worth the biological costs of this responsiveness" ( $p$. 15). This trait benefits relationships in just the ways that Aron described: the HSP looks out for their non-HSP counterpart by doing the emotional work and being aware of the subtleties, thereby allowing the non-HSP to focus on their own strengths (Aron, 1997; Aron, 2000).

Highly Sensitive People also seek those with similar temperaments to their own, however, and there are certainly benefits from such a dynamic (Aron, 2000). In a list on the 
strengths of a relationship with two HSPs, Aron writes, "you understand each other", "you are comfortable together", "you are thorough in your efforts at communication", "your partner will raise your self-esteem, "by loving each other, most HSPs are learning to love themselves more", and "you will be able to go deeply into your feelings, especially those that need healing, and usually be thoroughly understood" (Aron, 2000, p. 154-155). Many of these benefits go along with the way that any couple with similarities would appreciate: the ability to understand one another and to be comfortable in your mutual identity (Gottman, 1994; Aron, 2000; Cain, 2012). For HSPs, however, these similarities are especially beneficial. Where in some cases they may be the partner doing much of the emotional labor or communication maintenance, a bond with two Highly Sensitive partners might mean an ease of understanding and greater depth of intimacy (Aron, 2000).

The Highly Sensitive Person has many desirable characteristics in the realm of romantic relationships, following many of the rules set for "success". They are able to experience emotions and admiration more deeply, process this emotion, remain aware of themselves and their partner, and communicate such thoughts in such a way to bolster intimacy within a bond (Gottman, 1994; Gottman, 1999; Aron, 2000). Beyond this, they are able to note when changes need to be made in the environment, pick up on nuances within the dynamic, and self-evaluate what they may need moving forward. These are traits and skills that should be highlighted and encouraged, in HSP relationships and non-HSP relationships alike.

However, the intersections of romantic relationships and Highly Sensitive People are not all roses: there are certainly challenges that arise. In order to best balance this appraisal on the Highly Sensitive Person in love, it is important that I next discuss the conflicts that can and do come into play. 


\section{Negative Characteristics of an HSP Partner}

"Up to now I have been upbeat about HSPs, speaking of our conscientiousness, loyalty, intuition, and insight. But I would do you a disservice if I did not also say that HSPs have as much or more reason to reject and deny parts of themselves" (Aron, 1997, p. 161). This particular quote is from Dr. Elaine Aron, who also goes on to write, “[...] HSPs also can be dismal partners for many reasons, none of them incurable" (Aron, 2000, p. 30). As it is important to balance the good and the bad within relationships, so it is important to balance the best and most challenging traits of the Highly Sensitive Person. Sensitivity, as we have found, can be a great gift: the HSP has many positive characteristics and brings many benefits to a romantic relationship. In the words of Carl Jung, "Excessive sensitiveness very often brings an enrichment of the personality... Only when difficult and unusual situations arise, the advantage frequently turns to a great disadvantage, since calm consideration is often disturbed by untimely feelings" (Jung, 1913; Aron, 2004). Untimely feelings are inherent to the experience of the Highly Sensitive Person thanks to the depth of their emotional range and their susceptibility to overarousal (Aron, 1997). Though these are conflicts that can be understood with time and careful consideration, the HSP needs plenty of both: space to be alone and separate from conflict, as well as a partner that deeply understands their needs (Aron, 1997; Aron, 2000). In the case of overarousal, a status that is relatively frequent considering the HSP's low threshold, the HSP can be unreachable (Aron, 2000). The only way to deflect such distance is to minimize the potential of overarousal, such as by taking time-outs (Gottman, 1994; Aron, 2000) or by avoiding conflict riddled with personal attack (Aron, 1997; Aron, 2000). This is easier said than done, as it is common to assume that there is "something wrong" with ones partner if they are very sensitive and unable to remain in conflicts other couples may be more equipped to handle (Cain, 2012, p. 164). As Dr. Gottman expressed 
in his Four Horsemen, there is undoubtedly concern when conflict leads to contempt, contempt to defensiveness, and finally to stonewalling: the ultimate "time-out" (Gottman, 1994; Aron, 1997). The HSP is susceptible to such stonewalling, if only in an attempt to remove themselves from the source of their overarousal (Aron, 2000). Gottman talks extensively in his work about the subject of "flooding", a concept that acts as something of a synonym to the experience of overstimulation. Flooding is described as when “[...] you feel so overwhelmed by your partner's negativity and your own reactions that you experience "system overload", swamped by distress and upset. You may become extremely hostile, defensive, or withdrawn. Once you're feeling this out of control, constructive discussion is impossible" (Gottman, 1994, p. 110). Though Gottman implies that flooding is a point that any individual or couple can reach, he does mention that some "feel flooded at the mere suggestion of a complaint" (p. 110). Because the HSP has such a low tolerance for stimulus, and even less when it is a personal affront (Aron, 2000), they experience flooding more often and the challenges that go along with it. "Once your physical arousal reaches a certain level it becomes virtually impossible to think calm, soothing thoughts or to appreciate your spouses' point of view," (1994, p. 116) says Gottman. This inability to reestablish positive interaction with ones partner can at times make the necessary ratio of 5:1, positivity: negativity a seemingly impossible feat for the HSP (Gottman, 1994).

It is no wonder that the HSP can suffer from low self-esteem, a factor that would make anyone susceptible to the threat of partner criticism (Aron, 1997). "As I have emphasized," Aron writes in her work, "HSPs are prone to low self-esteem because they are not their culture's ideal. So sometimes they consider themselves lucky if someone wants them at all” (Aron, 1997, p. 147). These challenges can cause major conflict in any relationship: a partner with low selfesteem faces an uphill battle every time their partner implies anything is wrong with the way 
they are (Aron, 1997; Aron, 2000). Thus, this must be taken into careful consideration in an HSP relationship: they may already believe there to be something wrong about themselves, and their partner - HSP or otherwise - must take note so as not to force their already tender state into disequilibrium (Aron, 1997).

Alongside having low self-esteem, the HSP can also struggle immensely with having little to no boundaries with others (Aron, 1997; Aron, 2000). "Many HSPs tell me that a major problem for them is poor boundaries - getting involved in situations that are not really their business or their problem, letting too many people distress them, saying more than they wanted, getting mired in other peoples' messes, becoming too intimate too fast or with the wrong people", concludes Aron (1997, p. 61). Without boundaries, a partnership can easily cross over into troubled waters. There must be individuation for both partners to grow and progress within the partnership (Gottman, 1994; Gottman, 1999; Aron, 2000; Schnarch, 2009), otherwise they are often riddled with the conflict of codependence.

Though one might not inherently consider being too helpful a problem area, the HSP can at times get into trouble when they attempt to be a "super HSP". "Over and over I have seen HSPs compensate for their not being the "ideal" man or woman by becoming Superman or Superwoman." Aron notes, "It is pretty hellish for your partner, too, if you have found time to have one" (Aron, 2000, p. 58). Dr. Elaine Aron considers this desire to go above and beyond to be compensation; the HSP wants to do everything and more, at the risk of their own wellbeing and that of their partner (Aron, 2000). If an HSP is attempting to overwrite their natural aversions to overarousal, they may end up doing the exact opposite: finding themselves instead in a constant state of overstimulation, with little to no patience or energy to connect (Aron, 1997; Aron, 2000). 
Connection is, in many ways, a strength of the HSP: however, when faced with problematic attachment styles in combination with their high levels of sensitivity, they may face certain difficulties (Aron, 1997; Aron, 2000). Though having an insecure attachment style is not a hallmark of the HSP's experience, their susceptibility to troubling environments or traumas can cause them to suffer. As Aron mentioned in reviewing her research on this dynamic, "while I found a slight tendency for more HSPs than non-HSPs to show one of the non-secure attachment styles as adults, that does not mean the trait creates the situation. It probably reflects the way a sensitive child is more aware of the subtle cues in any relationship" (Aron, 1997, p. 70). In understanding the relationship high sensitivity has to depression, anxiety, neuroticism, and problematic attachment styles, one may refer back to what Aron had to say about their early bonds and the significance they hold:

As we already have discussed, HSPs' relationships to everyone and everything are greatly affected by the nature of their childhood attachments to their first caretakers. Since only about 50 to 60 percent of the population enjoyed a secure attachment in childhood (a shocking statistic, really), those of you HSPs who tend to be very cautious about close relationships (avoidant), or very intense in them (anxious-ambivalent), can still consider yourselves quite normal. (p. 143)

This outlines a distinct possibility for a romantic relationship involving an HSP: either there is too much attachment and emotional intensity, or too little. In best understanding ones partner, it is crucial to understand their needs. For some HSPs, their adaption to their condition has been through needing more intensity. Aron writes that, “[...] intensity can also stop the relationship. Extremely intense love is often rejected by the beloved just because it is so demanding and unrealistic. The one being loved often feels smothered and not really loved at all in the sense that 
his or her feelings are being considered.” (1997, p. 141). For others, they may need the opposite: more time-outs, more space. Aron mentions "[that] another frequent problem in a close relationship with a less sensitive partner or friend is your greater need for solitude, just to think and digest the day. The other may feel rejected or simply still want your company" (Aron, 1997, p. 155). It may begin to feel as though a Highly Sensitive Person cannot win: either they have too much of a need for closeness, or too little. It is important, then, to reiterate that the key to solving these differences is to understand them.

As was briefly outlined when mentioning differences in temperament, there is much to gain from understanding and learning from contrast between partners (Gottman, 1994; Cain, 2012). Though many HSPs need space to return to equilibrium due to their capacity to feel emotions so intensely, there are more extreme forms of the HSP derived from other factors. It is important that we and the public not confuse high sensitivity with "neuroticism", which includes certain types of intense anxiety, depression, over attachment, or avoidance of intimacy, and are usually due to a troubled childhood. True, some of us were dealt both hands in life - high sensitivity and neuroticism - but the two things are not at all the same. This confusion of sensitivity with neuroticism and the effects of childhood trauma is one reason for some of the negative stereotypes of HSPs (that we are by nature always anxious, depressed, and so on). (Aron, 1997, p. 66)

As Aron writes, not all HSPs function with this combination, and therefore their differences with their partners, non-HSP or otherwise, may not be so stark. However, even in the case that the two individuals seem to exist in vastly different emotional landscapes, the relationship is still salvageable (Gottman, 1994; Aron, 1997; Cain, 2012). Any relationship can have conflicts based on the separate experiences of each partner; many individuals vary in mental health, attachment 
style, personal needs, and temperament (Gottman, 1994; Aron, 1997; Gottman, 1999; Aron, 2000; Cain, 2012). There is so much to gain from understanding these dissimilarities, however, and through the means of communication and healthy boundaries (Aron, 1997; Aron, 2000), a relationship with differences can be strengthened rather than torn apart. Next, I will briefly outline other possibilities within partnerships with varying combinations of individuals: the HSP and the non-HSP, the ways gender comes into play, and what this might mean for a romantic relationship.

\section{Additional Factors}

In my writing so far, I have mentioned several possible interactions between partners, including differences in attachment style (secure, insecure-avoidant, insecure-anxious), personality types (traits like neuroticism or extraversion), and most importantly, HSP versus nonHSP. However, this particular combination, that of an HSP and a non-HSP, deserves further attention, as it is one of the ways that an HSP feels their inherent traits to be most salient: in comparison to a person who does not experience them (Shaver \& Brennan, 1992; Aron, 1997; Aron, 2000).

In examining an HSP and non-HSP relationship, it would first be wise to refer back to Dr. Aron's own writings on the subject. In her works on Highly Sensitive People, Aron attempts to highlight the importance of understanding these differences, and offers advice on how to move forward whilst respecting each individual's experience. "The problem is," writes Aron, "that as an HSP/non-HSP agrees to live more separate lives, in accord with the degree of stimulation each enjoys, this can lead to estrangement if taken too far" (Aron, 2000, p. 132). In Aron's research, it became apparent that the differences inherent to this pairing require some compromise. Too much separation, however, can cause the two to barely exist in each other's 
lives at all (p. 132). She goes on to describe other challenges that may come up as a result of these differences, including, "[that] non-HSPs seem to want more intimacy, HSPs to want more time alone", "both of you have to deal with your (the HSP's) times of overarousal", "both of you have to deal with spillover from vicariously living the other's very different experience" and "the HSP will have more difficulties at work" (p. 133-134). Many of these examples have been examined in earlier sections, including the ways in which HSPs attempt to lower their level of arousal; at times, needing to remove themselves entirely (Aron, 1997; Aron, 2000). As for the HSP having more difficulties at work and in their own individual lives, this may be a result of flooding, or it may be through their attempts to avoid such sensations, as in the case of the Super HSP (Aron, 1997). In many ways, the Super HSP has much to do with gender. These HSPs attempt to fit the complex gender roles culturally assigned to them, though the task may seem impossible in the face of their sensitive nature (Aron, 1997).

How, then, do gender and gender roles come into play as an HSP? “All HSPs, men or women, are more aware of what other people are feelings, what they want and need", writes Aron (2000, p. 56). There is an emphasis in Aron's work on the fact that there are as many men as women born Highly Sensitive (p. 50), despite the reality that more women report themselves to be HSPs. There are many hypotheses for this possibility, most having to do with cultural expectations of men (Aron, 1997; Aron, 2000). Though not all cultures subscribe to the logic of the masculinity bias (Aron, 1997), many men in Western society feel a pressure to be "manlier" or simply less sensitive (Smith, 2014). As a result, regardless of whether they might exist somewhere on the spectrum of sensitivity, a man may be less willing to report himself as such. In relationships, he may be even less willing to stay in touch with this emotionality, at the risk of stigma from society or even his partner (Gottman, 1994; Aron, 2000; Smith, 2014). As the prior 
study on male anxiety had mentioned, the insecurities a male partner faces in the relationship may be a greater predictor in its ending (Porter \& Chambless, 2016). These facts are made even more challenging when Gottman's research supports that men are more likely to experience flooding, as they have been found to be more physiologically sensitive to stimulus than they let on (Gottman, 1994).

Excluding for a moment same-sex partnerships, it would be an obvious assertion that a male/female HSP/non-HSP relationship would have its differences. The combinations may involve a Highly Sensitive male partner with a non-HSP female partner, a Highly Sensitive female partner with a non-HSP male partner, or a female and male HSP (Aron, 2000). The question, then, is how might these partnerships interact, as well as where the challenges may arise. As a result of the stigma already existing against sensitivity, there may be ways that female HSPs confirm stereotype threat (Aron, 1997; Aron, 2000): because there is already an existing stereotype that women are the more emotional partner, a female HSP may feel especially vulnerable when faced with a male non-HSP partner (Aron, 2000, p. 47). On the opposite end of the stigma, however, male HSPs may face the judgment attached to being an emotional man (Aron, 2000, p. 50); in which case, these HSPs may feel less apt to explain themselves to their non-HSP partner.

"I think the HSP has to take charge [...] in order not to have anyone else to blame later. After all, you are the one who knows best how you are feeling and what you can enjoy", writes Aron, in reflecting on the choices an HSP with a non-HSP partner has to make (Aron, 1997, p. 154). There are many ways for these combinations to find harmony. Communication with ones partner is crucial: it allows the HSP to express their experience of a situation, an experience both 
partners very well may not share. Self-awareness is also quite important, in order to best know where ones limits may lie (Aron, 2000).

After all, a partnership has many opportunities to grow. In returning to the idea of a "successful" romantic relationship, it would be tempting to imply that it ought to be a state of constant contentment between both partners. However, this is not possible, regardless of if the relationship involves an HSP or otherwise (Gottman, 1994; Aron, 2000). Conflict will always exist, as well as inherent partner differences. In the grand scheme of things, it is less important that there are differences than it is that both partners understand one another. Next, I will examine whether the good and the bad of loving an HSP can weigh out for the better, as well as how to move forward even when the opposite is suspected to be true.

\section{The "Success" of an HSP Relationship}

For those that identify as Highly Sensitive, it is good news in reporting that the HSP is by no means doomed to an unhappy or "unsuccessful" relationship. However, as has been outlined in prior sections, this does not mean that there are not obstacles inherent to such romantic endeavors. To briefly outline the best elements of the Highly Sensitive Person, it is important to mention their inherent self-awareness, their awareness of others and high levels of empathy, their immense ability to feel and experience depth of emotion, and their ability to communicate such emotion in efficient and caring ways (Aron, 1997; Aron, 2000; Kaufman, 2015). Although communication, caring, and awareness are some of the most crucial elements of a "successful" relationship, overarousal or flooding can override any well-wired system, as in the case of the Highly Sensitive (Gottman, 1994; Aron, 1997; Aron, 2000). The negative repercussions of Highly Sensitive characteristics are all linked to this lowered threshold for stimulation. Overarousal can cause HSPs to withdraw or grow irritable in preparation for overarousal (Aron, 
2000), actions that connect back to the difficulties outlined by Gottman and the Four Horsemen (Gottman, 1994). These "Horsemen”, or rather, chronological steps leading to relationship dissatisfaction, have much to do with a lack of communication and a withdrawal. These are both active risks when an HSP partner feels overwhelmed by stimulus, their own emotions, or, in some cases and conflicts, their partners (Gottman, 1994; Aron, 2000).

As I have examined, there are certainly some combinations of Highly Sensitive People who will have more difficulties than others; for example, those with difficult attachment styles or childhood trauma may experience heightened symptoms and therefore more extreme challenges to work with (Aron, 1997). These particular individuals are no more destined for a life without happy romantic relationships than those with mental disorders, however. There are similarities in the distress that an HSP with an anxious attachment style might feel to an individual with Borderline Personality Disorder; neither party, however, is unable to be understood (Shaver \& Brennan, 1995; Jovev et al, 2011).

The vital component here is in playing upon so many of the HSP's strengths so as to minimize their difficulties. Though an HSP may feel incredibly overwhelmed in states of overarousal, they are still actively analyzing their inner thought processes and therefore are still, in large part, aware of what is going on (Aron, 1997; Aron, 2000). The HSP needs to become in tune with themselves in these moments. It is imperative that they attempt to understand what may have triggered their overstimulation. They also must learn not overcompensate (as in the case of the Super-HSP) or avoid stimulus altogether (as in isolation). This process of selfcorrection is one that must be shared and understood by the HSP's partner (Gottman, 1994; Aron, 2000; Zeff, 2004). After all, any relationship, involving an HSP or otherwise, can benefit from having a deep and loving understanding of each partner's experiences. Heightened 
sensitivity is a trait that dictates an individual's view of the world, not unlike extraversion. It is not an inherently good or bad thing, rather, an absolute neutral (Aron, 1997; Aron, 2000). Partners may, for example, have much to gain from incorporating certain extroverted sensibilities into their lives as well as introverted. So it is true with non-HSP partners and their counterparts: both can prosper from acknowledging the other's truth (Aron, 2000; Cain, 2012).

Romantic relationships are, in so many ways, about a balance: just as Gottman described in the 5:1 ratio of positivity, so a ratio must exist between the many qualities that go hand in hand with intimacy (Gottman, 1994; Schnarch, 2009). The HSP does not tip the scales so long as they remind themselves and their partners how best to find equilibrium once more (Aron, 2000). Next, I will outline how best to move forward: as an HSP in love, as a non-HSP looking to understand or incorporate Highly Sensitive traits, and as a researcher looking to fill in the gaps.

\section{Discussion}

First and foremost, there are certain methods to improve any relationship, Highly Sensitive or otherwise (Gottman, 1999). As Gottman described, many of these methods involve communication, an area in which an HSP partner may be more adept in (Aron, 2000); but moreover, the right ratio of compassion, positivity, and the ability to calm oneself, even in challenging situations (Gottman, 1994; Gottman, 1999; Schnarch, 2009). One relationship expert, Dr. David Schnarch, describes this as having a "quiet mind, calm heart": the ability to "calm yourself down, soothe your own hurts, and regulate your own anxieties" (Schnarch, 2009, p. 72). This works in conjunction with Gottman's advice: his studies emphasize communication through the means of "love maps", turning "toward each other instead of away", and by creating "shared meaning" (Gottman, 1999). Gottman also supports the need for positivity and love by encouraging partners to "nurture your fondness and admiration" and to "let your partner 
influence you" (1999). Finally, in times of conflict, his principles suggest solving "your solvable problems" and attempting to "overcome gridlock" (1999). Finding "success" within a relationship, then, is about the duality of the self and the partner: a meeting point between two people. Individuals must be able to know themselves and take care of themselves, so as to best take care of another.

Whether or not a relationship involves a person who identifies as Highly Sensitive, a romantic relationship or marriage benefits from this depth of understanding. A partnership must include a willingness to know the experience of the other person involved (Schnarch, 2009). This willingness and depth is, in so many ways, the definition of intimacy that was outlined in prior sections (Gottman, 1999; Schnarch, 2009). When a partner is able to understand the other, with clarity and compassion, they are also more able to feel loved and understood (Gottman, 1994; Gottman, 1999; Berscheid \& Regan, 2005). “After all, when both partners feel their grievances get a sympathetic hearing, compromise is a lot easier" (Gottman, 1994, p. 39).

Conflict and misunderstanding do happen. As I have found through countless sources, it is a natural and organic part of a relationship (Gottman, 1994; Gottman, 1999; Aron, 2000; Chapman, 2017). Gary Chapman, best known for his creation of "the 5 love languages" (Chapman, 2017), has studied romantic relationships and notes, "[...] marriage relationships are constantly changing. Attitudes shift, emotions fluctuate, and the way spouses treat each other ebbs and flows between loving and not so loving" (Chapman, 2005, p. 6). In his book on what he describes as the "seasons" of marriage, Chapman writes:

My experience, both in my own marriage and in counseling couples for more than thirty years, suggest that marriages are perpetually in a state of transition, continually moving from one season to another - perhaps not annually, as in nature, but just as certainly and 
consistently. Sometimes we find ourselves in winter - discouraged, detached, and dissatisfied; other times, we experience springtime, with its openness, hope, and anticipation. On still other occasions we bask in the warmth of summer - comfortable, relaxed, enjoying life. And then comes fall with its uncertainty, negligence, and apprehension. The cycle repeats itself many times throughout the life of a marriage, just as the seasons repeat themselves in nature. (2005, p. xii)

It is true that romantic relationships are subject to phases, some more difficult than others. HSPs, aware of so many subtleties, often are aware of these changes within their relationships, too (Aron, 2000). Some HSPs may be more or less inclined to face their conflicts head on. It is in these moments that the HSP must remember to be kind to themselves: a task that is, at times, rather difficult (Aron, 1997; Aron, 2000). "People who have low self-esteem, which includes many HSPs, can reverse this error in the conclusions they draw about themselves and others. When we do something wrong, it's our flawed personality; when someone else does, it was an accident - the situation," writes Aron, "But consider your own situation" (Aron, 2000, p. 124).

It is imperative that the HSP actively practices self-care and taking care of themselves, as these are cognitive tools to bolster oneself for whatever situation or relationship lies ahead. "Both self-love and other-love increases when we don't make too many personality attributions about ourselves or others, when we recognize that people cannot be completely explained with a label such as shy, rude, or even Highly Sensitive, and that situations are complex, rich, often unpredictable, and infinitely interesting" (Aron, 2000, p. 124). It is true that there is always more going on than meets the eye: as is absolutely the case for the Highly Sensitive population. Part of "quiet mind, calm heart" is being innately aware of ones own characteristics (Schnarch, 2009). For the HSP, this means knowing what might cause overarousal or flooding, as well as what will 
help. Half of healing is healing oneself: when the HSP learns to accept themselves, extend kindness towards themselves even when experiencing flooding, and to feel that their sensitivity is a strength and not a weakness, only then they are able to take care of their partner and express their needs most effectively (Gottman, 1994; Aron, 2000, Schnarch, 2009).

This may mean extra work on the part of the HSP partner when in a relationship. There are ways to calm oneself down, particularly in times of relationship distress. "It's important for the HSP to realize that even if you cannot control the Type A environment, you do have the power to control your reaction to it", writes Ted Zeff, psychologist and author of The Highly Sensitive Person's survival guide (2004). Though an HSP might not be paired with a "Type A" non-HSP partner, they will always be somewhat more at risk of being affected by their partner's insensitivities (Aron, 2000; Zeff, 2004). In the case of becoming overwhelmed or overstimulated by their partner, the HSP may benefit from practicing certain exercises to calm themselves down. "As an HSP, you'll need to utilize specific behavior modification exercises to disengage from the Type A environment. Techniques such as meditation and deep breathing will help you disconnect from the fast-paced world we're living in. Unfortunately, most people don't want to modify their lifestyle, even if it's causing them tension and anxiety" (Zeff, 2004). It may seem easier for an HSP is such a situation or environment to disengage, as Zeff described in his "survival guide", or to try to get away from the source of the flooding (Gottman, 1994; Zeff, 2004). However, it is exactly in these moments that an HSP should not attempt to separate themselves from their partner. Rather than breaking away, these are opportune moments for an HSP to become aware of their inner thought processes, to shift their perspective, and to practice compassion and love through explaining this experience to their partner (Gottman, 1994; Aron, 2000). "The pivotal pressure that is the keystone to this cascade of distance and isolation is from 
feeling flooded. If you can learn to calm these feelings of being emotionally overwhelmed by your partner, it opens the way for other ways to repair your marriage. To relieve the sense of being flooded, you need to calm down, to change distress-maintaining thoughts, and to speak and listen non-defensively," writes Gottman. "Letting your spouse know in so many little ways that you understand him or her is one of the most powerful tools for healing your relationship" (Gottman, 1994, p. 169; p. 195).

This is where communication comes back into play: it is critically important for both partners to turn “towards", as in one of Gottman's Seven Principles, rather than away from one another (Gottman, 1999). When an HSP is feeling overwhelmed, they benefit not only from being able to determine the source of this overarousal, but from being able to communicate how best to move out of this discomfort to their partner (Aron, 2000). More often than not, maintaining a dialogue - a positive one, at that - is enough to return an HSP partner to a state of equilibrium (Aron, 1997; Aron, 2000).

For some HSPs, however, talking through their discomfort is the last thing that they want to do in a period of heightened arousal. Disappearing or retreating, even when in an honest attempt to find that inner balance, is a callback to Gottman's "stonewalling", the fourth and most toxic Horsemen, and the breaking point for many relationships (Gottman, 1994). It is in couples with a partner like this, however, where communicating personal needs is even more necessary. Rather than assuming that a conflict will never be resolved due to one partner (typically, the HSP) needing to remove themselves, this would be a perfect opportunity to set ground rules (Aron, 1997; Aron, 2000). Aron writes that couples with HSP partners should be encouraged to "discuss how you will handle conflict before it arises and how you did afterward" (Aron, 2000, p. 159). To return to the concept of enforcing "time-outs", Aron suggests dictating what amount 
of space would help, and when. "Explain whatever intimacies are too much for you, right now or generally," she writes. "Be gently honest and clear that this does not mean you love your partner less. [...] It is certainly true that all people have preferences; all people need to stay in an optimal level of arousal. Explore your partner's preferences and needs for the right level of arousal in the same spirit, and work out what's best for both of you" (Aron, 2000, p. 82).

If these exercises, both separate and between partners, seem too challenging for a relationship, sometimes looking for outside help is the best remedy. Couple's counseling may instigate the communication that is otherwise at a standstill. "Couples often need help with their relationships," writes Aron, "Yet research has found that only 1 percent of those who divorce have ever sought marital counseling. Don't be one of the 99 percent" (Aron, 2000, p. 196). In other circumstances, partners just may need time to understand their bond: no one relationship looks the same (Gottman, 1994). So long as the members of the romantic relationship are able to understand and affirm one another, as well as communicate their differences respectfully, they will undoubtedly figure out the rhythm that works best for them (Gottman, 1999; Aron, 2000).

As for non-HSPs with HSP partners, there is much to gain from offering additional support. After all, an HSP has so much to offer: as was initially found, the HSP brings emotional depth, self-awareness, and partner awareness to the table (Aron, 1997; Aron, 2000). By affirming an HSP partner, the non-HSP has access to all of the most wonderful qualities within their partner. The HSP offers love through the same lens as all of their other emotions: with immense depth, sensitivity, and complexity (Aron, 1997; Aron, 2000). The potentiality of such a bond with an HSP is a truly exciting one: it may lead both partners to feel new depths of being understood, affirmed, and seen (Aron, 2000). "You will change each other," so says Aron. "You will teach each other. You will include the other into yourself. Research shows that two 
dissimilar partners will each change their personalities over their lifetime, becoming more similar and thus adding new dimensions to themselves, while the personalities of two similar partners tend to stay the same" (Aron, 2000, p. 128). Similarly, Carl Jung writes, "the meeting of two personalities is like the contact of two chemical substances: if there is any reaction, both are transformed" (Jung, 1933, p. 49). The non-HSP, then, may evolve to incorporate such HSP dimensions as self-awareness and emotion into bonds with other non-HSPs.

Any partnership must "[...] gain the wisdom to know the difference between what you can and can't change. Yes, you want to grow and change, and hopefully your partner does too. You want to help each other in this by urging change. But one of the greatest steps in growth is to accept each other - to accept the inevitable disappointment of our partner's inherited limits, to appreciate that every person is a "package deal" and "when you choose a partner, you choose a set of problems" (Aron, 2000, p. 150). For some, those "problems" might be a troubled background, a mental disorder; for the HSP, the "package deal" will always involve a lowered threshold to become overaroused (Aron, 1997). The love that holds a romantic relationship together, however, weathers these challenges: by utilizing the tools of self-comforting and knowledge, compassionate understanding and listening, and excellent communication, a bond is altogether likely to be as "successful" as one can be (Gottman, 1994; Aron, 1997; Gottman, 1999; Aron, 2000).

In collecting research for this thesis, much of the information provided on the Highly Sensitive Person and Sensory Processing Sensitivity has come from Dr. Elaine Aron and her husband, Arthur (Aron, 1997). Some of the psychological community has begun to pick up on the terminology, including the works of Dr. Ted Zeff and others (Dunn, 2001; Zeff, 2004; Liss, 2008). As briefly mentioned, I have found innumerous pop-psychology articles in smaller 
publications, offering diagnoses and tips with titles like, "Are you Highly Sensitive”, "Top 10 survival tips for the HSP”, "Being sensitive doesn't make you weak", and "Beautiful minds: shades of sensitivity" (Biali, 2011; Kaufman, 2015; Kapoor, 2015; Hill, 2017). Even Oprah Winfrey, popular television icon and activist, had Dr. Elaine Aron in the spotlight, around the time when the term had first taken off (The Boston \& New England HSP Group, 2012; Winfrey, 2012). However, there are certainly gaps in information on the trait. There are many articles that say the same things; these articles are excellent tools for basic understanding, but do not provide an academic or detailed framework with which to understand it psychologically. There have been some studies on Sensory Processing Sensitivity, largely conducted by Aron, but the field clearly has room to expand. It is my hope that there will be further research conducted on HSPs: whether offering further case studies on romantic relationships, understanding how other social factors such as race or sexuality may come into play, or simply putting it to the test against other conditions that mimic the HSP such as the equally young term "empath" (Orloff, 2017). Additionally, there is always room for more academic research on the vast expanse of romantic relationships. Though I was limited in covering committed relationships within certain bounds, there are so many more facets to the modern relationship that ought to be explored. In the future, I hope to delve into more research on HSPs and romantic relationships, as there is infinite room to understand and investigate both.

\section{Conclusion}

Highly Sensitive People are unique. Dr. Elaine Aron describes the trait that affects some 15 to 20 percent of the population as "a blessing to you and others" (Aron, 1997, p. 231). HSPs are sensitive: emotionally, cognitively, and physiologically. They have wonderful attributions, as well as areas that they must understand and work with over the course of their lives, whether in 
romantic relationships or otherwise. The task of the HSP is not unlike the task of the romantic partner: to love, to understand, and to work through the rest with compassion. A non-HSP partner is able to offer their HSP partner this generosity, just as the HSP partner does in return. These are all negotiable terms: every relationship is different. However, the most helpful and "successful" ways to be in a relationship involve these components (Gottman, 1999; Aron, 2000). Love is, after all, a balance. "Success" and contentment come from keeping a ratio of positivity that leaves both partners feeling taken care of. An HSP is able to communicate their depth, and non-HSPs can gain much through practicing the same (Aron, 2000).

Playwright William Shakespeare famously wrote, "The course of true love never did run smooth" (1600). So it is in the case of loving the Highly Sensitive Person: though there may exist challenges, the rewards would deem any romantic relationship a great "success". 


\section{References}

Ackerman, J. M., Griskevicius, V., \& Li, N. P. (2011). Let's get serious: Communicating commitment in romantic relationships. Journal of Personality and Social Psychology:

Interpersonal Relations and Group Processes, 100(6), 1079-1094. doi:10.1037/a0022412

Akiskal, H. S. \& Benazzi, F. (2006). The DSM-IV and ICD-10 categories of recurrent (major) depressive and bipolar II disorders: Evidence that they lie on a dimensional spectrum. Journal of Affective Disorders, 92(1), 45-54. doi:10.1016/j.jad.2005.12.035

Aron, E. N. (1997). The highly sensitive person: How to thrive when the world overwhelms you. New York, NY: Broadway Books.

Aron, E. N. (2000). The highly sensitive person in love: Understanding and managing relationships when the world overwhelms you. New York, NY: Harmony Books.

Aron, E. N. (2004). Revisiting Jung's concept of innate sensitiveness. Journal of Analytical Psychology, 49. 337-367. doi:0021-8774/2004/4903/337

Aron, E. N., Aron, A., \& Jagiellowicz, J. (2012). Sensory processing sensitivity: A review in light of the evolution of biological responsivity. Personality and Social Psychology Review. 1-21. doi:10.1177/1088868311434213

Aron, E. N. (2017). FAQ: Is sensory processing (or integration) disorder (SPD) the same as sensory processing sensitivity (SPS)? Retrieved from http://www.thehighlysensitiveperson.com.

Benham, G. (2006). The highly sensitive person: Stress and physical symptom reports. Personality and Individual Difference, 40(7), 1433-1440. doi:10.1016/j.paid.2005.11.021

Bernard, J. (1934). Factors in the distribution of success in marriage. American Journal of Sociology, 40(1), 49-60. doi:10.1086/216651 
Berscheid, E. S. \& Regan, P.C. (2005). The psychology of interpersonal relationships. New York, NY: Routledge.

Biali, S. (2011, May 21). Top 10 survival tips for the highly sensitive person (HSP). Retrieved from https:/www.psychologytoday.com/blog/prescriptions-life/201105/top-10-survivaltips-the-highly-sensitive-person-hsp.

Brown, B. (2010). The gifts of imperfection: Let go of who you think you're supposed to be and embrace who you are. Center City, MN: Hazelden Publishing.

Cain, S. (2012). Quiet: The power of introverts in a world that can't stop talking. New York, NY: Broadway Books.

Chapman, G. (2005). The 4 seasons of marriage: Secrets to a lasting marriage. Carol Stream, IL: Tyndale House Publishers, Inc.

Chapman, G. (2017). About Dr. Gary Chapman. Retrieved from: http://the5lovelanguages.com.

Coontz, S. (2005). Marriage, a history: From obedience to intimacy, or how love conquered marriage. New York, NY: Penguin Books.

Corsini, R. J. (1993). A marriage counseling success test. Individual Psychology: The Journal of Adlerian Theory, Research \& Practice, 49(3, 4), 406.

Cox, F.D. \& Crosby, J. (1972). A marriage wake: Myths that die hard. American marriage: A changing scene? (p. 85-90). Dubuque, IO: WM. C. Brown Company Publishers.

Cox, F.D. \& Hunt, M. (1972). The future of marriage. American marriage: A changing scene? (p. 244-257). Dubuque, IO: WM. C. Brown Company Publishers.

Definition of “sensitive”. (2017). Retrieved from https://www.merriamwebster.com/dictionary/sensitive. 
Definition of "mental illness". (2017). Retrieved from https://www.merriamwebster.com/dictionary/mental\%20disorder.

Demir, M. (2008). Sweetheart, you really make me happy: Romantic relationship quality and personality as predictors of happiness among emerging adults. Journal of Happiness Studies, 9(2), 257-277. doi:10.1007/s10902-007-9051-8

Dryer, D. C. \& Horowitz, L. M. (1997). When do opposites attract? Interpersonal complementarity versus similarity. Journal of personality and social psychology, 72 (3), 592-603. doi:10.1037/0022-3514.72.3.592

Dunn, W. (2001). The sensations of everyday life: Empirical, theoretical, and pragmatic considerations. Journal of Occupational Therapy, (55), 608-620. doi:10.5014/ajot.55.6.608

Ganahl, J. (2015, July). Heightened sensitivity. Retrieved from http://spiritualityhealth.com/articles/heightened-sensitivity.

Gottman, J. (1994). Why marriages succeed or fail and how you can make yours last. New York, NY: Fireside.

Gottman, J. (1999). The seven principles for making marriage work. New York, NY: Three Rivers Press.

Hargrave, T. D. \& Pfitzer, F. (2011). Restoration therapy: Understanding and guiding healing in marriage and family therapy. New York, NY: Routledge.

Hill, M. (2017, April 17). The social challenge of highly sensitive people. Retrieved from https://www.sensitiveevolution.com/social-challenge-sensitive-people/. 
Jovev, M., Chanen, A., Green, M., Cotton, S., Proffitt, T., Coltheart, M. \& Jackson, H. (2011). Emotional sensitivity in youth with borderline personality pathology. Psychiatry Research, 187(1-2), 234-240. doi:10.1016/j.psychres.2010.12.019

Jung, C. (1933). Modern man in search for a soul. Abingdon, OX: Routledge.

Kapoor, S. (2015, January 12). Being sensitive doesn't make you weak. Retrieved from http://houghtcatalog.com/seema-kapoor/2015/01/being-sensitive-doesnt-make-youweak/.

Kaufman, S. B. (2015, May 4). Beautiful minds: Shades of sensitivity. Retrieved from https://blogs.scientificamerican.com/beautiful-minds/shades-of-sensitivity/.

Lally, M. (2015, October 12). Highly sensitive people: a condition rarely understood. Retrieved from http://www.telegraph.co.uk/wellbeing/health-advice/highly-sensitive-people/.

Lewis, J.M. (1985). Marriage as a search for healing: Theory, assessment, and therapy. New York, NY: Brunner/Mazel Inc.

Liss, M., Mailloux, J. \& Erchull, M. J. (2008). The relationships between sensory processing sensitivity, alexithymia, autism, depression, and anxiety. Personality and Individual Differences, (45), 255-259. doi:10.1016/j.paid.2008.04.009

Major, B. \& O’Brien, L.T. (2005). The social psychology of stigma. Annual Review of Psychology, (56), 393-421. doi:10.1146/annurev.psych.56.091103.070137

McCandless, D. \& Sullivan, L. (2016, November). Varities of intimate relationships. Retrieved from http://www.informationisbeautiful.net/visualizations/the-varieties-of-intimaterelationship/.

Miller, L. J. \& Schaaf, R. C. (2008). Sensory processing disorder. Encyclopedia of Infant and Early Childhood Development. (127-136). doi:10.1016/b978-012370877-9.00142-0 
Miller, L. J. (2014). Sensational kids: Hope and help for children with sensory processing disorder (SPD). New York, NY: Penguin Group.

Orloff, J. (2017). The empath's survival guide: Life strategies for sensitive people. Boulder, CO: Sounds True.

Pinel, E. C. (1999). Stigma consciousness: The psychological legacy of social stereotypes. Journal of personality and social psychology, 76(1), 114-128.

Porter, E., Chambless, D. L., \& Keefe, J. R. (2016). Criticism in the romantic relationships of individuals with social anxiety. Behavior Therapy.

Porter, E. \& Chambless, D.L. (2016). Social anxiety and social support in romantic relationships. Behavior Therapy, 48(3), 335-348. doi:10.1016/j.beth.2016.12.002

Psychometric success (2017). The 'Big 5' aspects of personality.

Rehman, U. S., Gollan, J., \& Mortimer, A. R. (2008). The marital context of depression: Research, limitations, and new directions. Clinical Psychology Review, 28, 179-198. doi: 10.1016/j.cpr.2007.04.007

Ronningstam, E. (2010). Narcissistic personality disorder. Corsini Encyclopedia of Psychology. doi:10.1002/9780470479216.corpsy0577

Schnarch, D. (2009). Intimacy \& Desire: Awaken the passion in your relationship. New York, NY: Beufort Books.

Schutte, N.S., Malouff, J.M., Bobik, C., Coston, T.D., Gresson, C., Jedlicka, C., Rhodes, E., \& Wendorf, G. (2001). Emotional intelligence and interpersonal relations. The Journal of Social Psychology, 141(4), 523-536. doi:10.1080/00224540109600569

Schwartz, A. (2012, December 11). The loneliness of alexithymia. Retrieved from: https://www.mentalhelp.net/blogs/the-loneliness-of-alexithymia/. 
Shakespeare, W. (1600). A midsummer night's dream.

Shaver, P.R. \& Brennan, K. A. (1992). Attachment styles and the "Big Five" personality traits: Their connections with each other and with romantic relationship outcomes. Personality and Social Psychology Bulletin, 18(5), 536-545. doi:10.1177/0146167292185003

Shaver, P.R. \& Brennan, K. A. (1995). Dimensions of adult attachment, affect regulation, and romantic relationship functioning. Personality and Social Psychology Bulletin, 21(3), 267-283. doi:0146167295213008

Shumway, D. R. (2003). Modern love: Romance, intimacy, and the marriage crisis. New York, NY: New York University Press.

Smith, S. T. (2014, November 10). The difference between highly sensitive and hypersensitive. Retrieved from https://www.psychologytoday.com/blog/ironshrink/201411/thedifference-between-highly-sensitive-and-hypersensitive.

Smolewska, K. A., McCabe, S. B., \& Woody, E. Z. (2006). A psychometric evaluation of the highly sensitive person scale: The components of sensory-processing sensitivity and their relation to the BIS/BAS and "Big Five". Personality and Individual Differences 40(6), 1269-1279.

Synonyms for "contentment". (n.d.) Retrieved from http://www.thesaurus.com/browse/contentment.

The Boston \& New England HSP Group. (2012). HSPs in the news: Now on Oprah. Retrieved from http://boston-hsp.blogspot.com/2012/12/hsps-in-news-now-on-oprah.html.

Westermarck, E. (1926). A short history of marriage. New York, NY: Humanities Press, Inc. Winfrey, O. (2012). Quiz: Are you too sensitive? Retrieved from http://www.oprah.com/omagazine/am-i-too-sensitive-highly-sensitive-person-quiz_2. 
Zeff, T. (2004). The highly sensitive person's survival guide: Essential skills for living in an overstimulating world. Oakland, CA: New Harbinger Publications, Inc. 